\title{
Michel Brix, «Frenhofer et les chefs-d'oeuvre qui restent inconnus»
}

\section{Marco Stupazzoni}

\section{(2) OpenEdition}

1 Journals

\section{Edizione digitale}

URL: https://journals.openedition.org/studifrancesi/37922

DOI: $10.4000 /$ studifrancesi.37922

ISSN: 2421-5856

\section{Editore}

Rosenberg \& Sellier

\section{Edizione cartacea}

Data di pubblicazione: 15 décembre 2004

Paginazione: 630

ISSN: 0039-2944

\section{Notizia bibliografica digitale}

Marco Stupazzoni, «Michel Brix, «Frenhofer et les chefs-d'oeuvre qui restent inconnus»», Studi Francesi [Online], 144 (XLVIII | III) | 2004, online dal 30 novembre 2015, consultato il 08 mai 2021. URL: http:// journals.openedition.org/studifrancesi/37922 ; DOI: https://doi.org/10.4000/studifrancesi.37922

Questo documento è stato generato automaticamente il 8 mai 2021.

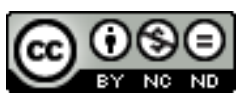

Studi Francesi è distribuita con Licenza Creative Commons Attribuzione - Non commerciale - Non opere derivate 4.0 Internazionale. 


\title{
Michel Brix, «Frenhofer et les chefs- d'oeuvre qui restent inconnus»
}

\author{
Marco Stupazzoni
}

\section{NOTIZIA}

MICHEL BRIX, «Frenhofer et les chefs-d'oeuvre qui restent inconnus», in Écrire la peinture entre XVIII et XIX $^{e}$ siècles, études réunies et présentées par Pascale AURAIX-JONCHIÈRE, Clermont-Ferrand, Presses Universitaires Blaise Pascal, «Révolutions et Romantismes», $\mathrm{n}^{\circ} 4,2003$, pp. 241-252

1 Le Chef-d'œuvre inconnu si annovera senza dubbio tra i testi balzachiani che hanno maggiormente stimolato la riflessione critico-letteraria e artistica. Ma quale nuova interpretazione è ancora possibile offrire oggi di questo racconto filosofico dopo che i grandi orientamenti della critica contemporanea hanno visto nel Chef-d'oeuvre una sorta di "art poétique" del romanticismo? E quale significato assumerebbe, da questo punto di vista, la figura di Frenhofer, incarnazione dell'ambizione balzachiana «de parvenir à une vision totalisante du réel, de révéler au monde un art prométhéen, lequel rivaliserait avec la vie»? (p. 241)

2 In questo interessante studio, non privo di originalità, Michel Brix si interroga sulla piena legittimità di tali interpretazioni in relazione al significato da attribuirsi ad alcune tematiche verso cui la critica ha concentrato in modo particolare la sua attenzione (il tema della follia o quello del fallimento dell'artista e del suo catechismo estetico). Se la ricerca mistica intrapresa da Frenhofer impone all'artista di «dépouiller les choses de leur apparence extérieure» (p. 247), il leitmotiv del suo discorso sulla pittura pare fondarsi paradossalmente su un'idea di creazione tesa «vers un extrême réalisme» (p. 248): l'eroe balzachiano, puntualizza bene l'A., «ambitionne de produire une réplique de la nature, de rendre la vie réelle de la jeune femme dont il trace le portrait» (ibid.). 
$3 \mathrm{Ma}$, «à force de chercher la réalité - scrive Picasso -, il arrive aux ténèbres» (p. 249): agli occhi di Balzac, l'artista non è un demiurgo e un'estetica (profeticamente vicina all'idea di poesia concepita da Mallarmé) che tende all'assoluto «ne peut aboutir qu'à des oeuvres vides, absentes, sans sujet» (p. 251). 